\title{
Azul pintado de azul. Leyendas de artistas sin obras
}

\author{
Filippo Fimiani \\ Università degli Studi di Salerno \\ fimiani@unisa.it
}

RESUMEN: En el verano de 1947, Yves Klein, Claude Pascal, Armand Fernández, sentados en la playa de Niza: contemplan el mar y el cielo azul, no hacen nada, y hacen declaraciones sobre el arte que llegará, sobre el Arte y el Gran Estilo del Futuro. A partir de ese momento, y de esas palabras, cada una de sus vidas cambia radicalmente: se convertirá en una vida nueva, una vida de artista sin obras, hecha solo de palabras, narraciones, gestos. En ese episodio, nace el Nouveau Realisme y la voluntad artística de la superación del problema del arte según el Modernismo y la Action Painting. En ese episodio y en su narración, hecha sucesivamente por los tres jóvenes artistas, se puede localizar el nacimiento del propio y auténtico mito del artista contemporáneo.

PALABRAS CLAVE: Yves Klein; Performatividad; Manifiestos de Artista; Índice; Fotografía; Nuevo Realismo.

\section{Blue Painted in Blue. Fables of Artists without Works}

ABSTRACT: In the summer of 1947, Yves Klein, Claude Pascal, Armand Fernandez, sit on the beach in Nice: looking at the sea and the blue sky, doing nothing, and making statements on the art to come, the Art and the Big Style of the Future. From that moment on, from those words, their lives would change radically and become completely new: a Vita Nova, the life as an artist without artworks, just words, stories, gestures. It was a moment that saw the birth of the Nouveau Realisme movement and the artistic will to overcome the problem of art and the philosophy of art, according to Modernism and the Action Painting. In that episode and in the après-coup narrative, told by three young artists, we can grasp the emergence of a true contemporary artistic myth.

KEYWORDS: Yves Klein; Performativity; Artist Manifestoes; Indexicality; Photography; Nouveau Realisme.

Creyeron en mí. Ya solo el gesto abstracto fue suficiente. Creo que soy un genio, y sin embargo no produzco nada sensacional. Superé todas esas ideas; para mí [...], son como fotografías que el tiempo ha vuelto amarillas.

\section{Un verano en el mar}

Tres muchachos -ninguno de más de veinte años: Yves Klein, Claude Pascal, Armand Fernandez-, tres amigos del alma apasionados del judo, pierden el tiempo en un verano tórrido pero sereno; hablan, se hacen promesas que parecen bromas, como ocurre a esa edad y en esa estación. Pasean por la Promenade des Anglais y llegan a la playa, donde se sientan, con los pantalones remangados y los pies desnudos en la arena tibia; ojos y rostros dirigidos al cielo y el mar, de un celeste compacto, y hacia el calor del sol, invisible pero que la piel siente.

De este episodio (O' Neill, 2012: 48 y ss.), los protagonistas proporcionaron distintas versiones, pequeñas fábulas de artista al mismo tiempo autobiográficas y ficticias, entre la propaganda retrospectiva y la propuesta programática. A partir de

Cómo citar este artículo: FIMIANI, Filippo: «Azul pintado de azul. Leyendas de artistas sin obras», Boletín de Arte-UMA, n. 38 , Departamento de Historia del Arte, Universidad de Málaga, 2017, pp. 35-44, ISSN: 0211-8483, DOI: http://dx.doi.org/10.24310/BoLArte.2017.v0i38.3188 
estas historietas, crearé por mi parte otra pequeña historia, atenta a las relaciones entre cuento y manifiesto, narración y testimonio, y concentrada en cuestiones conjuntamente de retórica, poética y filosofía del arte, de un arte sin obras de arte.

Si el «aquí y ahora» de la escritura autobiográfica siempre está relacionado con la alteridad y con otro lugar, y con la recolocación de uno mismo en el tiempo y en el espacio, en esta especie de escena primaria balnearia en la que están ambientados nuestros cuentos, y en la que los deseos cobran los rasgos efímeros de una utopía realizada (Urbain, 1994: 68 y ss., 153 y ss., 300 y ss.), salen a la luz dos elementos importantes en la auto-narración del nacimiento del artista: la naturaleza y la juventud.

La ribera de Niza es un paisaje mirado a través del filtro de la cultura visual, de una artialisation in visu (Roger, 1997; Luginbühl, 2007), y es un espacio vivido por medio de usos y costumbres, in situ, en el que hechos y valores conviven en una estetización de la vida ordinaria. El cielo sin nubes de ese día de verano al mismo tiempo banal y excepcional, que Klein (2003: 299, 310) ${ }^{1}$ describe como su obra más grande y bella, no es entonces un elemento del cosmos natural -al contrario, los pájaros amenazan con agujerear su lienzo ilimitado- sino de un mundo de artefactos y prácticas culturales. "La continuidad del azul, afirma, es el gran estilo» (Klein, 2003: 340). Esta cualificación estética en segundo grado de la naturaleza -ya mediada por la historia cultural- como arte, implica una doble legitimación: del acto lingüístico improductivo, asumido como artístico, y de quien lo pronuncia, de alguien que habla -quizás con palabras ajenas: aquí Nietzsche-, pero no hace, y es reconocido como artista, sin obras.

La operación que Klein pone en escena tiene que ver con la artification -que propone Nathalie Heinich (Heinich y Shapiro, 2012: 267-299) para distinguirla de la artialisation de Alain Roger, que de todos modos presupone la naturaleza-, es decir, tiene que ver con el convertirse en arte de objetos, sitios y acontecimientos pertenecientes al mundo histórico de las prácticas culturales, gracias a dinámicas discursivas y pragmáticas, aleatorias y duraderas, simbólicas e institucionales. La indeterminación de las fronteras entre arte y no-arte es central en el arte contemporáneo y en los relatos de estos jóvenes artistas en ciernes, todos ellos comprometidos en una estrategia que alterna eliminación y reapropiación. En el caso de Klein, en el que me detendré, el futuro artista que se firmará Yves le Monochrome seguramente tiene presente el nominalismo duchampiano y la función de la firma (Heinich, 2008), por ejemplo en la célebre propuesta, del año 1916, de usar el Woolworth Building en construcción como un ready-made ${ }^{2}$.

Sin embargo, Klein es todavía más extremo, porque el gesto que indica el cielo no tiene referente y su ostensión deíctica elimina toda forma de relación estética, de contemplación y de interpretación. Cuando pretende expulsar a los pájaros que cruzan y estrían el cielo, mostrando de esta manera la profundidad de la tercera dimensión, Klein niega ante todo la contemplación de lo bello natural con su hundimiento en el azul al mismo tiempo uniforme y abstracto, entendido quizás, todavía según los cánones del Modernismo, como modelo a imitar con el fin de alcanzar la soberana cualidad sensible de una pintura plana y monocroma, o como epifanía no figurativa de una trascendencia metafísica. Pero Klein rechaza también y sobre todo la mirada que contempla en cuanto tal, que es gaze y no glance, porque no es una simple ojeada de bañista ocioso. La mirada firme dirigida al cielo azul y calmo es relacional, puesto que instituye y legitima un campo visual delimitado, enmarca y consagra un espacio separado de lo demás, del ambiente o fondo circundante, como objeto de una observación cuidadosa e intensa, ya sea desinteresada o práctica.

Tal y como nos recuerdan en varias ocasiones Louis Marin (1993: 20; cfr. Fimiani, 2009a: 222-224) y Daniel Arasse (1998a: 56 y ss.; 1998b: 84-85; 2004: 63-64), el verbo latino contemplare sería sinónimo de contueri, compuesto por el sufijo intensivo con- y tueri, ver, del que también derivaría el sustantivo templum. "Templo» ${ }^{3}$ es, originariamente, la porción de cielo cuadrada o rectangular que los augures circunscribían visualmente con un bastón, esperando que por ella pasaran los pájaros, cuyas trayectorias, velocidad y número, se entendían como signos aleatorios y mensajes opacos con un significado divino recóndito pero legible, como jeroglíficos misteriosos pero inteligibles. Natural o artística, templum sería todavía y en todo caso una obra a la espera de la mirada de un espectador y de su atención, y por ende de su deseo y de sus proyecciones psicológicas y emotivas, sería, en resumidas cuentas, eso a lo que el ver y el interpretar de un sujeto deberían feliz y eficazmente corresponder ${ }^{4}$.

Cuando Klein habla del cielo en cambio como un lienzo inmaculado, sin adornos y sin ningún tipo de aspecto o 
signo que contemplar, excluye toda acción o posición subjetiva, creadora o interpretativa. Postula un pictor fictus más que un artista -o un espectador- como Deus artifex, como productor de artefactos o como protagonista de las experiencias que están material u objetivamente vinculadas con objetos. Después del año 1945, en lugar de la mitografía del artista moderno, reconstruida un decenio antes por Ernst Kris y Otto Kurz (1995: 23-53; cfr. Bätschmann, Groblewski, 1993), apareció una mitomanía de un artista que, muertas ya las vanguardias, todavía construye una narración legendaria de la invención -de descubrimiento y hallazgo casual- de su talento, pero que ya no cree en el poder demiúrgico de sus manos y de la técnica artística, sino que, por el contrario, crea con ironía efectos y significados ante todo en las palabras y en los discursos en torno al arte. El «muro monocromo y azul» del que habla Pascal es lo contrario del «muro de pintura» informe del Frenhofer balzaquiano, personaje de ficción central en la «fábula del arte moderno» (Ashton, 1980: 82-85), de la Action Painting y del Expresionismo abstracto.

\section{Relatos de juventud}

«Era la edad en la que todos los adolescentes quieren poseer el universo". Las palabras de De la spiritualité à la conquête affective de l'espace de Arman (en Ottman, 2010: 20-21) sintetizan una condición histórica y una mítica, una juventud obligada, por así decirlo, a desear cosas y mercadería después de la pobreza y del vacío de la Guerra, y una edad de la inocencia sin memoria de la excesiva plenitud de sus horrores y fantasmas (Castle, 1983: 148; O’ Neill, 2012: 78 ss.; Hahn, 1998: 138-140)5 . Más despreocupado y burlón es en cambio Claude Pascal, abiertamente contrario a toda connotación literaria, iconográfica y temática, sobre lo marino pintoresco y lo sublime: «Ante este mar imbécil -escribe, quizá soñando con Maldoror, en A l'occasion d'une rétrospective du Monochrome: préface à la petite mort de trois adolescents (en Ottman, 2010: 22-23, y Stich, 1994: 18-19)-, en el que se consumen los viejos de Francia y el arte, nosotros teníamos unos veinte años... Jóvenes... abstinencia... gusto por la hazaña desmedida... contemplación del universo azul...». Lo que los tres amigos encuentran en la playa de Niza, en ese verano de 1947, «es la naturaleza compartida, ordenada. A cada uno su reino. Sin que se haya hecho ningún gesto. A cada uno su medida. Sin que el adulto haya aún nacido. Un trazo, un gran trazo, hasta el final del mar, marcando lo azul y confirmando la amistad, como ese viaje extraordinario que hizo Yves Klein hasta el otro lado del cielo para firmarlo y apropiarse de él, porque la materia pertenece al primero que la descubre», como un tesoro escondido bajo la arena y desenterrado con palitas de plástico de colores. La repartición simbólica de la naturaleza se hace al mismo tiempo a partir de sugestiones místico-esotéricas, sacadas de los textos de los Rosacruces, y filosóficas, inspiradas en las lecturas quizás ya hechas de los libros de Bachelard acerca de la imaginación material y los elementos ${ }^{6}$. Esta división corresponde a un reparto de las artes: a Arman le correspondería la tierra y sus riquezas, es decir, la escultura; a Claude Pascal, el aire, esto es, la palabra poética; a Yves Klein, el cielo y el infinito, a saber, el azul inmaterial de la pintura.

Aunque en nombre de una juventud a la que la guerra ha obligado a un entusiasmo renovado, al mismo tiempo excesivo y forzoso, transitorio y estratégico, en Klein el gesto disciplinado siempre cargará con la sombra de la pose de artista, la seriedad convivirá con la ironía o la burla, el pacto de confianza con el público quedará duplicado por el embeleco de la ficción (Grojnowski, Riout, 2015: 247-253). Por otra parte, en él juventud y entusiasmo son consignas polémicas y polisémicas ${ }^{7}$. Para el primer número de Soulèvement de la jeunesse, de Isidore Isou, Klein escribe sobre «revolución de los entusiastas» y «utopía del entusiasmo», sobre el instante absoluto y efímero del color y sobre la «juventud realmente «joven»» y «eterna» (Klein, 2003: 20-21, 324-27; cfr. Cabañas, 2015: 124-127, y Stich, 1994: 48-49). La «aventura monocroma» y las "aventuras incompletas» encontradas y reconocidas en Hurlement en faveur de Sade, del año 1952, comparten el carácter destructivo e iconoclasta -también en su caso, comparado por Debord a Malevitch (Cheetman, 2005)-, «el espectador, privado de todo, [queda] además privado de imágenes» ${ }^{8}$, pero no de sensibilidad.

Es sintomática la forma en que Klein (2003: 299, 310) evoca el episodio de Niza en Manifeste de l'Hotel/The Chelsea Hotel Manifesto:

Cuando era adolescente, por el año 1946, fui a firmar con mi nombre el otro lado del cielo, durante un fantástico viaje realístico-imaginario. Ese día, me tendí en la playa de Niza, y me puse a odiar a los pájaros que volaban aquí y allá en 
mi hermoso cielo azul sin nubes, iporque trataban de hacer agujeros en la más bella y grande de mis obras!

Si aquí Klein no nombra a nadie más y cuenta que está solo, en otro lugar (O’ Neill, 2012: 49), en el margen de una reproducción de una fotografía sacada en Niza con Pascal, describe la experiencia con los amigos como «el tiempo del encuentro del vaciamiento de la personalidad». ¿Por qué este desplazamiento del yo individual al anonimato de la comunidad y a la evacuación de toda peculiaridad? Si el Manifeste de l'Hotel Chelsea parece extremar que un retrato valoriza necesariamente el rostro o la figura como carácter individual y único, la anotación lacónica sobre la fotografía parece radicalizar la sintonía expresiva y de pose de los dos amigos y hacer de semejante imagen una representación de sujetos indistintos e impersonales. Los dos amigos quedarían despersonalizados, pero no porque estén sumidos en su propia interioridad o en su actividad artística, sino porque exhiben su propia y anhelada identidad social de artistas y exigen de los demás que los reconozcan como tales en la escena pública y mundana. ¿Cómo controlar la veracidad, la validez y el valor de la relación entre narración e imagen, cuando ni la una ni la otra aspiran a ser documentación de origen factual o el relato de la fabricación de una obra material, sino que más bien afirman una vocación y una voluntad sin vacilaciones y atestiguan un acontecimiento sin acciones?

En la escritura poetológica de Klein, y en particular en la narración de su conversión en artista, legitimación y manipulación se mezclan conscientemente. Entre sus estrategias más relevantes, me inclino a nombrar las citas y los recursos a los nombres propios de artistas, escritores y filósofos, y el empleo de la cronología: obsérvese, sin salirnos de nuestro ejemplo, que el encuentro veraniego en la playa está fechado de distinta manera por cada uno de los protagonistas, 1946 o 1947, y la fotografía de Klein y Pascal en Niza es, según Pascal, del año 1947, mientras que, para Arman, es de 1951 [1].

\section{Decir, indicar, hacer}

Las narraciones de ese encuentro no se proponen solo como el relato de una experiencia única, sino también como un instrumento de propaganda de sí mismos, individual y de grupo; sin embargo, ninguna de ellas tiene el tono de programa o proyecto, y ninguna de sus frases se deja remitir a las modalidades de lo performativo.

Una escritura autobiográfica, o una narración en primera persona, no es un manifiesto. Un manifiesto presupone un poder comunicativo y una eficacia tendencialmente intersubjetiva y amplia de la palabra, indisociable de sus resultados. Aunque en singular, la palabra del manifiesto -si no es tan solo el reflejo de una ideología o un programa preexistente, como acontece con un manifiesto artístico de vanguardia ${ }^{9}$ - tendría algo más que un efecto perlocutivo en el destinatario, le otorgaría una posición, un papel, una tarea, un destino. El discurso del manifiesto sería por su misma vocación indistinguible de la conducta que quisiera cumplir (Demers, McMurray, 1986), sería tendencialmente normativo y ambiguamente indeciso entre un proceso de subjetivación y una sujeción: no solo le haría creer que percibe y siente, piensa y hace, sino que realmente le haría percibir y sentir, pensar y hacer de una manera distinta a la del sujeto universal, si bien interpelado individualmente (AAW, 2013).

El poder de la palabra del manifiesto permite ser algo nuevo y convertirse en alguien distinto al que se era antes -para nosotros: convertir un objeto ordinario, o un lugar banal, en una obra de arte, y una obra de arte radicalmente distinta de todas las anteriores, y transformar a alguien que no hace nada realmente especial o especializado, en un artista. Ese poder se basa en una interpelación cuyos efectos ni son mecánicos ni se pueden dar por descontados. La eficacia con que el poder performativo del aparato lingüístico del manifiesto se funda en una historicidad y una cultura radica en una sedimentación de pre-comprensiones y costumbres, de saberes y usos. Semejante proceso de legitimación, en el que la cualificación estética no antecede sino que llega después de la palabra del artista, no supone un ámbito o una clase de objetos y géneros ya dados -notoriamente: las obras de arte y los artistas-, ni tampoco los distribuye jerárquicamente; ambiguo e indecidible, ese proceso es una práctica cultural que evade un constructivismo social rígido (como en Bourdieu, 1982). La fuerza del manifiesto, o de la declaración del artista como género literario (Abastado, 1980) y acto discursivo ambiguo y contradictorio (Mangone, Warley, 1993: 9 ss. y 56 ss.; Glicenstein, 2015), está vinculada al contexto histórico, cultural y social, inclusive al 
contexto restringido del mundo del arte y de sus instituciones (Sobrino-Freire, 2001), pero no está subordinada ni se deja deducir de él, ni en términos de dominación ni tampoco en términos de necesidad o causa. Por el contrario, esa fuerza siempre está en acción en una escena de legitimidad al mismo tiempo condicionada y libre, donde produce una autoridad y una acreditación creíbles y en las que se cree pero que, sin embargo, no se conforman a las creencias y a las normas dadas sino que se confrontan con ellas, en una relación de transformación recíproca.

Sin convenir con las condiciones de posibilidad de su misma existencia -condiciones históricas y culturales, sociales y pragmáticas, estilísticas y simbólicas, sensibles y perceptivas-, la toma de palabra del artista vive de la falta de coincidencia entre lo que dice y sus usos, de la diferencia entre performativo -también como «efecto-manifiesto» secundario- y contexto. Lo que el artista dice se afirma como promesa de una reinscripción imprevista o hasta subversiva del poder de las formas discursivas, capaz no solo de nombrar, etiquetar y legitimar, de fijar y replicar, sino también y sobre todo de crear nuevas prácticas de sentido y de hacer accesibles otras experiencias sensibles (Fimiani, 2012).

Las palabras de tres jóvenes amigos, al mismo tiempo autores, narradores y personajes, son una suerte de ficción cronística del manifiesto y de su intencionalidad (van den Berg, Grüttemeier, 1998). La voluntad de escritura de sus textos breves trasciende el testimonio estrecho de una experiencia personal, aspira a ser pública, apunta a una forma de reconocimiento que concierne a la calidad estilística y teórica de la narración, a la autenticidad y a la legitimidad de lo narrado, a la acreditación y a la autoridad del narrador. Las palabras de Arman, Pascal y Klein extraen parte de su fuerza de las referencias realistas a lo sucedido, sirviéndose ambiguamente de la vocación documental de la escritura autobiográfica por declarar y autentificar una instancia indexical del registro y de la restitución integral de la realidad con vistas a un contacto directo con lo inmediato factual. No sin ambigüedad, esta pretensión inoperante parece complementarse con otra, más abiertamente activa y utópica, que, en cambio, trata de invocar lo que no existe y construir lo real más profundo y el Sí mismo «en el azul», según El espíritu de la utopía (1918 y 1923) de Ernst Bloch (1977: 12-13) y Der blaue Reiter y Lo espiritual en el arte de Kandinsky (1911).

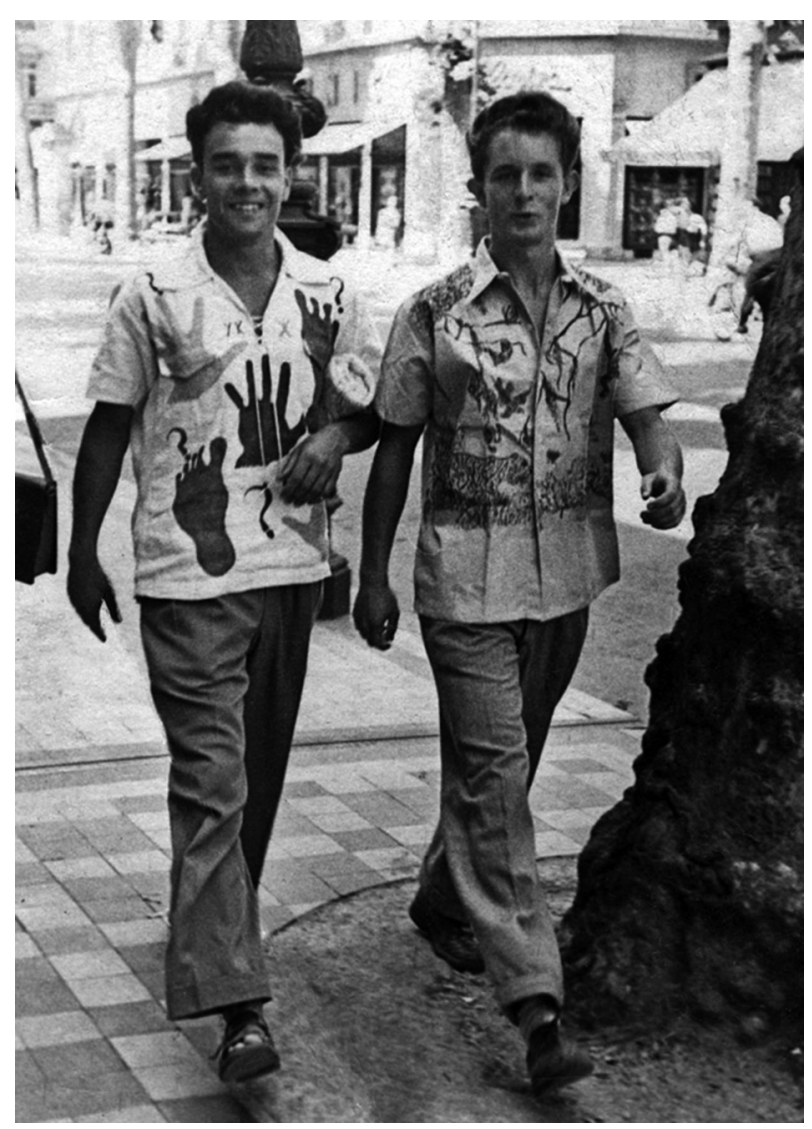

Yves Klein y Claude Pascal en Niza

\section{Rastros de lo inmediato}

Para comprender mejor la naturaleza y la función tanto de lo testimonial y de lo autobiográfico como del documento y del manifiesto en la poética y en la actividad artística de Klein, hay que integrar sus discursos con elementos no textuales y no verbales. Para medir mejor la relación entre arte y pensamiento visual, entre pintura como "cosa mental» y su esencia vivida, entre sensibilidad y experiencia estética, hay que completar las palabras del artista con sus acciones, poner junto a sus enunciados sus medios operativos, junto a sus declaraciones, sus operaciones.

Ya he recordado la leyenda de Klein de la imagen fotográfica sacada en compañía de Pascal, mientras caminan con paso cadencioso y aire altanero [1]. El futuro pintor lleva una camiseta con huellas de manos y pies y signos de puntuación, unos signos de interrogación; el futuro poeta, una 
camisa con motivos vegetales o fósiles y minerales también estampados, como retículas con hojas y raíces enredadas, y filamentos de cañas y frondas desecados o fosilizados. Estos signos que Klein imprime manualmente en las telas no son expresiones de un gusto personal o de una moda de verano. Son indicios de una vocación por la puesta en escena mundana y la auto-representación dandy del artista (Jones, 1995: 25-27), entre el disfraz infantil y la actitud estilizada, son muestras de una poética en la que son esenciales tanto la ignorancia del porvenir y lo cíclico de la naturaleza como la reproductibilidad y la serialidad. Son entonces, también, índices: tal y como la máquina fotográfica es un atributo del veraneante y el papel humano de la fotografía es cobrar un valor de uso historiográfico y social (como en Bourdieu, 1965; cfr. Floch, 1986: 16 ss.), los signos en las camisas estivales de los dos jóvenes artistas son, por un lado, testimonio del tiempo y prueba verídica, y por otro, elementos de una iconografía indexical y de una poética del rastro y de la impresión o, finalmente, de una escritura geológica y fotoquímica sin autor, que se repite en Klein.

En el año 1956, después de haber hallado la noción de «marca» de lo que es «fugitivo» e «indefinible» en el Journal de Delacroix, y después de haber dicho que «lo que necesita un artista es un temperamento de reportero [...] en el sentido fuerte de la expresión», Klein hace un balance retrospectivo: "la marca espiritual de los estados-momentos» son los Monocromes; la de los «estados-momentos de la carne», las Anthropométries, las «huellas separadas de los cuerpos de las modelos»; la de las «huellas de la naturaleza» -viento, lluvia, fuego-, la «marca de un suceso atmosférico", las Naturemétries (Klein, 2003: 282-286, 304306; cfr. Fimiani, 2009b).

En las muchas operaciones de des-especificación del medio realizadas y proyectadas por Klein, lo que queda disputado es el destino documental y el estatuto testimonial de la fotografía, es decir, su naturaleza de registro mecánico continuo y directo de lo visible y del ser en general, como si se tratara de una especie de escritura natural primera (Michaels, 2007; Schuller, 2016) y de «fotografía no humana» (Zylinska, 2017), resumiendo, de imágenes aqueropitas (Didi-Huberman, 1984; Mondzain, 1996: 121-139, 235-252, y 2002; Belting, 2005: 63-72; Broadfoot, 2012). A la luz de dicha experimentación, cabe decir que, mientras que Duchamp desacraliza el original con la firma de sus réplicas, la presencia real de Klein sigue siendo indispensable: solo él puede consagrar sus obras inmateriales. La operación artística, que no prevé obras de arte tangibles, no podría delegarse, sino que requiere la potencia creadora del artista. Como en el caso de los santos o de los místicos, se trata de una trascendencia situada más allá de la problemática del arte.

Este testimonio de lo irrepresentable, de lo inconmensurable y de lo no figurable (Alexandrova, 2017: 26-33), me parece análogo a la imitatio Christi, en el sentido de que instruye posturas y figuras de un estilo de vida ético. La misma incorporación testimonial vale, por un lado, en la ritualización performativa de la relación entre artista y público -realmente una comunión litúrgica, pero no ajena a la lógica institucional e irónica de Duchamp-, y, por otro, en el mecanismo del dispositivo fotográfico de fijación de la impresión de lo real circundante. A la letra, todos los elementos que participan en la experiencia estética son testigos: películas fotográficas sensibles, el artista, la obra, los espectadores están presentes en el evento estático, continuo y sin acciones, quedan tocados, modificados, conmovidos (Klein, 2003: 230, 154). No se trata de un testimonio ocular sino epidérmico, mejor dicho, carnal, porque la impresión de lo real a la que están expuestos los cuerpos -del artista, del público, de la obra- es una impregnación, esto es, una transformación profunda del «clima afectivo, puro, esencial de la carne» (Klein, 2003: 309).

Testigos, es decir, «fantasmas y extraños personajes que no pertenecen a nadie [...] y llenos de sensibilidad»: de este modo Klein (2003: 133) define las esculturas-esponjas de finales de los años cincuenta. De pequeñas dimensiones, azul o de otros colores, están inspiradas en las esculturas-basura de Dubuffet, en el límite de lo kitsch, y parodian la auto-narración legendaria de Matisse -que, contemporáneamente a la mucho más banal excursión en la playa de Niza, se describe en Polinesia incapaz de pintar, ocupado como estaba en absorber la luz y el color, al igual que una esponja con el agua, y reemplazaba al artista ocioso con la aventura feliz de la «esponja de Protógenes» narrada por Vasari. Al mismo tiempo antropomorfas y pre-humanas, son auto-retratos del artista y del espectador como testigo absoluto, sin obra pero lleno de historias, mitos y fábulas para adultos (Fimiani, 2010: 296-298).

[Traducción de María Lida Mollo] 


\section{Notas}

1 Ese "cielo puro y sin nubes» es al mismo tiempo pictórico, literario y filosófico, o pop y de la cultura de masas, y la firma de Klein se sobrepone a la de Giotto, Mallarmé y Bachelard, o a la del cantante Domenico Modugno (Klein, 2003: 136, 219).

2 Addock, 1985; Bonk, 1995; Nesbit, Sawlson-Gorse, 1999: 152-154; Gamboni, 2011: 123-124.

3 Cfr. Pauly, Wissowa, 1934: ad vocem; Müller, 1961: 60 ss.; Rykwert ,1988: 44-50. Entre las fuentes, Cic., de Div. II.18, Leg. 2.20-1, Liv., 1.18.7, y sobre todo Varro, de Ling. lat. 7, 5: Quaqua intuitierant oculi, a tuendo primo templum dictum: quo circa caelum qua attuimur dictum templum.

4 Recuerdo que kairós, el acontecimiento propicio al que tiene que corresponder [attagliare en italiano] la imagen verbal o visual, remitiría al verbo kéirein, que significa precisamente cortar [tagliare] y recortar [ritagliare].

5 Para una reconstrucción, Morris, Wilson, 1993: 25-52, y Bertrand Dorléac, Munck, 2012.

6 Cuando ya había publicado los estudios sobre la revêrie del agua (1941), del aire (1943), y de la tierra (1946); Klein afirmará haber recibido para su trigésimo cumpleaños L'Air et les songes, en coincidencia con la muestra La spécialisation de la sensibilité à l'état matière première en sensibilité picturale stabilisée, conocida como l'Exposition du Vide, de parte de Iris Clert el 28 abril de 1958.

7 Acerca de una historia cultural de la juventud, Pogue Harrison, 2014.

8 Es la frase que aparece en la pantalla negra de In girum imus nocte et consumitur igni, del año 1978.

9 Cfr. Asholt, Fähnders, 1997; Lyon, 1999; Ehrlicher, 2001; Somigli, 2003; Puchner, 2006. Para los manifiestos post-vanguardistas y la crisis del artista, Larue, 2008; Obrist; Lees; Peyton-Jones, 2009; Yanoshevsky, 2009.

\section{Bibliografía}

AA.W. (2013), Lignes, número especial Le maniféste, vol. 1, n. ${ }^{\circ} 40$.

ABASTADO, Claude (dir.) (1980), Les Manifestes, número especial de Littérature, n. ${ }^{\circ} 39$.

ADDOCK, Craig (1985), "Marcel Duchamp's Approach to New York: "Find an Inscription for the Woolworth Building as a Ready-Made"»,

Dada/Surrealism, vol. 14, n. ${ }^{\circ}$ 1, pp. 52-65.

ALEXANDROVA, Alena (2017), Breaking Resemblance: The Role of Religious Motifs in Contemporary Art, Fordham University Press, Nueva York 2017, pp. 26-33.

ARASSE, Daniel (1998a), «Cette minute depuis longtemps écoulée...», Anachroniques, Gallimard, París 2006, pp. 51-62.

- (1988b), «La solitude de Rothko», ibid., pp. 83-94.

- (2004), Histoires de peinture, France Culture/Denöel, París.

ASHOLT, Wolfang; FÄHNDERS, Walter (dir.) (1997), «Die ganze Welt ist eine Manifestation»: Die europäische Avantgarde und ihre Manifeste,

Wissenschaftliche Buchgesellschaft, Darmstadt.

ASHTON, Daniel (1980), A Fable of Modern Art, Thames \& Hudson, Nueva York.

BÄTSCHMANN, Oskar; GROBLEWSKI, Michael (dir.) (1993), Kultfigur und Mythenbildung. Das Bild vom Künstler und sein Werk in der zeitgenössischen Kunst, Akademie-Verlag, Berlín.

BELTING, Hans (2005), Das echte Bild. Bildfragen als Glaubensfragen, C.H. Beck, Múnich.

BERTRAND DORLÉAC, Laurence; MUNCK, Jacqueline (dir.) (2012), L'art en guerre. France 1938-1947: De Picasso à Dubuffet, Musée d'Art Moderne, París.

BLOCH, Ernst (1977), Geist der Utopie, Suhrkamp, Frankfurt am Main.

BONK, Ecke (1995), «Marcel Duchamp: The Woolworth Building as Readymade, January 1916», Grand Street, vol. 13, n. ${ }^{\circ}$, pp. $165-175$. BOURDIEU, Pierre (dir.) (1965), Un art moyen, Essai sur les usages sociaux de la photographie, Ed. de Minuit, París.

- (1982), Ce que parler veut dire, Fayard, París.

BROADFOOT, Keith (2012), «Barthes's Religious Substance. Photography and Acheiropoietos», Image \& Narrative, vol. 13, n. ${ }^{\circ} 3$, pp. $141-154$.

CABAÑAS, Kaira (2015), Off-Screen Cinema: Isidore Isou and the Lettrist Avant-Garde, University of Chicago Press, Chicago.

CASTLE, Frederick Ted (1983), «Accumulations by Arman», Art in America, vol. 17, n. ${ }^{\circ 11}$, pp. 136-142.

CHEETMAN, Mark A. (2005), «Matting the Monochrome: Malevich, Klein, \& Now», Art Journal, vol. 64, n. 4, pp. 95-108.

DEMERS, Jeanne; MCMURRAY, Line (1986), L'enjeu du manifeste/le manifeste en jeu, Le Préambule, Montreal.

VAN DEN BERG, Hubert; GRÜTTEMEIER, Ralf (dir.) (1998), Manifeste: Intentionalität, Rodopi, Amsterdam. 
DIDI-HUBERMAN, Georges (1984), «L'Indice de la plaie absente (monographie d'une tache)», Traverses, n. ${ }^{\circ}$ 30/31, pp. 151-163.

EHRLICHER, Hanno (2001), Die Kunst der Zerstörung: Gewaltphantasien und Manifestationspraktiken europäischer Avantgarden, Akademie Verlag, Berlín.

FIMIANI, Filippo (2009a), «Une esthétique imperceptible», Figures de l'art, vol. 16, pp. 217-240.

- (2009b), «Traces de pas. Atmosphères, affects, images», en ROUGE, Bertrand (dir.), L'Index, Presses Universitaires de Pau, Pau, pp. 177-188.

- (2010), «Embodiments and Art Beliefs», RES. Anthropology and Aesthetics, vol. 57/58, pp. 283-298.

- (2012), «Pour une poïétique de l'autre. Atmosphères, art, croyances», en BERTRAND, Denis; CLEMENT, Bruno; DOUMET, Christian (dir.), Croyance, créance, crédit, Herman, París, pp. 73-98.

FLOCH, Jean-Marie (1986), Formes de l'empreinte, Pierre Fanlac, Périgeux.

GAMBONI, Dario (2011), «Targeting Architecture: Iconoclasm and the Asymmetry of Conflicts», en FLECKNER, Uwe; STEINKAMP, Maike; ZIEGLE, Hendrik (dir.), Der Sturm der Bilder: Zerstörte und zerstörende Kunst von der Antike bis in die Gegenwart, Akademie Verlag, Berlín, pp. 119-124.

GLICENSTEIN, Jérôme (dir.) (2015), Manifestes, número especial de Marges, vol. 2, n. ${ }^{\circ} 21$.

GROJNOWSKI, Daniel; RIOUT, Denys (2015), Les Arts incohérents et le rire dans les arts plastiques, Corti, París. HAHN, Otto (1998), Avant-garde. Théorie et provocations, Chambon, Nîmes.

HEINICH, Nathalie (2008), «La signature comme indicateur d'artification», Sociétés \& Représentations, vol. 1, n. ${ }^{\circ}$ 25, pp. 97-106. HEINICH, Nathalie; SHAPIRO (dir.) (2012), De l'artification. Enquêtes sur le passage à l'art, Editions de l'EHESS, París.

KLEIN, Yves (2003), Le dépassement de la problématique de l'art et autres écrits, edición de SICHĖRE, Marie-Anne y SEMIN, Didier, Ecole Nationale Supérieure des Beaux-Arts, París.

KRIS, Ernst; KURZ, Otto (1995), Die Legende vom Künstler: ein geschichtlicher Versuch, (1934), Suhrkamp, Frankfurt am Main. JONES, Amelia (1995), “'Clothes Make the Man’: The Male Artist as a Performative Function», Oxford Art Journal, vol. 18, n. ${ }^{\circ}$, pp. $18-32$. LARUE, Anne (dir.) (2008), L'art qui manifeste, número especial de Itinéraires et Contacts de culture, n. ${ }^{\circ} 43$. LYON, Janet (1999), Manifestoes. Provocations of the Modern, Cornell University Press, Ithaca (NY).

LUGINBÜHL, Yves (2007), «La place de l'ordinaire dans la question du paysage», en LOLIVE, Jacques y BLANC, Nathalie (dir.), «Esthétique et espace public», Cosmopolitiques, vol. 15, pp. 173-178.

MANGONE, Carlos; WARLEY, Jorge (1993), El manifiesto: Un género entre el arte y la política, Editorial Biblos, Buenos Aires.

MARIN, Louis (1993), «L'être de l'image et son efficace», Des pouvoir des images, Seuil, París, pp. 9-24.

MICHAELS, Walter Benn (2007), «Photography and Fossils», en ELKINS, James (dir.), Photography Theory, Routledge, Londres, pp. $431-450$. MONDZAIN, Marie-José (1996), Image, Icône, Economie. Les sources byzantines de l'imaginaire contemporain, Seuil, París.

- (2002), "The Holy Shroud: How Invisible Hands Weave the Undecidable», en LATOUR, Bruno y WEIBEL, Peter (dir.), Iconoclash: Beyond the Image Wars in Science, Religion and Art, The MIT Press, Cambridge (Mass.), pp. 324-335.

MORRIS, Frances; WILSON, Sarah (dir.) (1993), Paris Post War: Art and Existentialism, Tate Gallery, Londres.

MÜLLER, Werner (1961), Die heilige Stadt: Roma quadrata, himmlisches Jerusalem und die Mythe vom Weltnabel, W. Kohlhammer, Stuttgart. NESBIT, Molly; SAWLSON-GORSE, Naomi (1999), "Concept of Nothing: New notes by Marcel Duchamp and Walter Arensberg», en BUSKIRK, Martha, NIXON, Mignon (dir.), The Duchamp Effect, MIT Press, Cambridge (Mass.), pp. 130-175.

OBRIST, Hans-Ulrich; LEES, Nicola; PEYTON-JONES, Julia (dir.) (2009), Serpentine Gallery Manifesto Marathon 2008, Verlag der Buchhandlung Walther König, Colonia.

O' NEILL, Rosemay (2012), Art and Visual Culture on the French Riviera, 1956-1971: The Ecole de Nice, Ashgate Publishing, Farnham. OTTMAN, Klaus (2010), Klein le philosophe, Editions Dilecta, París.

PAULY, August Friedrich von; WISSOWA, Georg (1934), Realencyclopädie der Classischen Altertumswissenschaft, Band VA, Halbband 9, J.B. Metzlersche, Stuttgart.

PUCHNER, Martin (2006), Poetry of the Revolution: Marx, Manifestos, and the Avant-Gardes, Princeton University Press, Princeton (NJ). POGUE HARRISON, Robert (2014), Juvenescence: A cultural History of our Age, University of Chicago Press, Chicago. 
ROGER, Alain (1997), Cour traité du paysage, Gallimard, París.

RYKWERT, Joseph (1988), The Idea of a Town: The Anthropology of Urban Form in Rome, Italy and the Ancient World, MIT, Cambridge (Mass).

SCHULLER, Kyla C. (2016), "The Fossil and the Photograph: Red Cloud, Prehistoric Media, and Dispossession in Perpetuity», Configurations, vol. 24, n. 2, pp. 229-261.

SOBRINO-FREIRE, Iria (2001), El manifiesto artístico: una aproximación al estudio de su funcionamiento en el campo de producción cultural, en línea: www.ensayistas.org/critica/mani-fiestos/iria.htm.

SOMIGLI, Luca (2003), Legitimizing the Artist: Manifest writing and European Modernism, University of Toronto Press, Toronto.

STICH, Sidra (dir.) (1994), Yves Klein, Museo Nacional Centro de Arte Reina Sofía, Museum Ludwig, Kunstsammlung Nordrhein-Westfalen, Madrid-Köln-Düsseldorlf.

URBAIN, Jean-Didier (1994), Sur la plage. Mœurs et coutumes balnéaires (XXe-XXe siècle), Payot, París.

YANOSHEVSKY, Galia (2009), "Three Decades of Writing on Manifesto: The Making of a Genre», Poetics Today, vol. 30, n. ${ }^{\circ}$ 2, pp. $257-286$. ZYLINSKA, Joanna (2017), Nonhuman Photography, MIT Press, Cambridge (Mass). 
